\title{
Social Engineering Program - MBA level: Designed for Global Education Demand
}

\author{
Melany M. Ciampi \\ Safety, Health and Environment Research Organization \\ São Paulo, Brazil \\ melany@,copec.org.br
}

\author{
Luis Amaral \\ Computer Graphics Center \\ Guimarães, Portugal \\ amaral@dsi.uminho.pt
}

\author{
Victor F. A. Barros \\ Science and Education Research Council \\ Braga, Portugal \\ victor@,copec.org.br
}

\author{
Claudio da Rocha Brito \\ Science and Education Research Council \\ São Paulo, Brazil \\ cdrbrito@,copec.org.br \\ Rosa Vasconcelos \\ University of Minho \\ Guimarães, Portugal \\ rosa@det.uminho.pt
}

\begin{abstract}
Following the new trend in education, more focused on a global perspective, COPEC - Science and Education Research Council is offering an MBA, online, in Social Engineering for all Countries of CPLP - Portuguese Language Countries Community. The goal is to cover these countries' engineers, which are also seeking for opportunities, as the majority are countries of growing economy based on their very rich resources. The idea of an online program is the possibility of reaching a broader audience and at the same time of enriching the experience of offering and implementing a program that can disseminate ideas and concepts, which fits the needs of the target audience. The Education Research Team of COPEC is convinced that Engineers with proper knowledge and skills can take action in order to solve social problems, as engineers are problem solvers.
\end{abstract}

Keywords - Online education; science and technology; research; public economy; population growth

\section{INTRODUCTION}

Political environment is full of challenges and crises of deep consequences to society as well as to the environment and it has a strong incidence in terms of decision making in any field. It means that taking decisions is becoming more and more complex and difficult due to the fact that the implications are felt in a faster way and in a larger community. For engineers, the decision process is even more complex once the implications have serious impact not only to the target customers but also to the society as a whole and to the environment. This is an aspect that shows the necessity for engineers to search for the acquisition of an ability to respond to social necessities having in mind the cultural aspects when developing a project.
The effects of this aspect in engineering education imply a different approach providing the future engineers with notions on policy, ethics and social sciences, which are so important to prepare them to the future work market that will require the respect and promotion of society and environment as assets [1].

Most of social groups have ambiguous understanding about science and technology; some understand it as responsible for the environmental deterioration and the voracious capitalism and others as the ones responsible for the better quality of life with the improvement of health systems, agricultural production and other accomplishments. Both perceptions are not far from the reality. In any case, the impacts can be seen along the history and more recently with the sophistication of the so called "information society". This particular "information society" shows how strong the impact of any technology introduced in the society can be. Real time communication and brutal amount of information available have changed drastically how people relate, make business and study [2].

The proposal of COPEC - Science and Education Research Council for the next five years is the offering of MBA by Distance Learning due to the new global education demand. The new programs will be delivered in Portuguese in a first moment, for all Countries of CPLP - Portuguese Language Countries Community. The idea is to cover these countries that also are seeking for opportunities, as the majority of them are growing and are very rich countries. The first group of programs is: MBA in Social Engineering and MBA in International Engineering Educator, both with International Recognition. 


\section{The SOCIAL ENGINEERING PROGRAM - MBA OFFERED BY COPEC}

Thanks to technology it is possible to conciliate work and studies once online programs are available for all and in every possible way. It is the era of the so called information society. The design of a project now requires knowledge about the social as well as the environmental impacts, so engineers should be capable of learning how to work close to governments and communities, addressing the results of the projects to solve social problems or at least to prevent new ones[3].

In response to this necessity, COPEC - Science and Education Research Council has developed a MBA in Social Engineering. It is an MBA program offered by distance that fulfills the urban demand of engineers to solve social problems which are outcomes of urbanization and environmental issues in cities.

The program is directed to engineers interested in acting in this field-offering consultancy for construction companies, industrial enterprises, city halls and governmental housing organizations, etc. It is an interdisciplinary program that prepares engineers to work in projects dealing with the social aspects of projects. The program is developed in modules: two modules per semester. The scores and the final project presentation online establish the final approval of a student. An online chat with students provides teaching and guiding for the development of projects in a broader perspective. The MBA is taught almost using case studies - whereby students discuss real dilemmas faced by actual companies. The debates are online and last for three or four days. The professor opens up the debate by asking questions and the students then begin discussing the case [4].

As the target audience is spread over different continents, the cases are discussed in an Internet forum. Students enter the discussion at the time that is best for them. It can be early in the morning before going to work, sometimes in the evening or even late at night. Usually they will be involved for two or three hours every day. The choice of asynchronous learning mode of delivery is due to the fact that so participants access course materials on their own schedule and so it is more flexible [5]. However, there is the possibility of a present module for pertinent seminars and visits to companies and sites with the goal to enhance the acquisition of knowledge and experience in the field.

\section{ASSESSMENT}

The evaluation of learning is continuous, prioritizing qualitative aspects related to the process of learning and student development observed during the conduct of the proposed activities.

To guide the evaluation process, make it transparent, able to contribute to the promotion and regulation of learning, it is necessary that the performance indicators are defined in terms of teaching, explained and negotiated with students from the beginning of the course, order directing all efforts of the technical staff, teachers and students themselves to achieve the desired performance.
The self-assessment will be fostered and developed through procedures that allow students to monitor their progress, as well as the identification of points to improve, practice deemed essential to learning autonomously [6].

The result of the evaluation process will be expressed in words:

- Optimal: able to play, highlighting the competencies required by the profile professional conclusion;

- Good: able to perform to the satisfaction, the skills required by the professional profile completion;

- Insufficient: still not able to play at least the required skills the professional profile of completion.

The endorsement will be awarded per module, considering the criteria and indicators performance related to the powers provided in each, which integrate professional competencies described in the profile completion below.

\section{ADMISSION REQUIREMENTS}

The basic candidate requirement for admission is:

To have a bachelor's degree in civil engineering. However, the program encourages applicants from diverse backgrounds, including (but not limited to) engineering, environmental science, management and economy. Applicants may need to complete prerequisite courses. A faculty advisor will determine the specific requirements on an individual basis depending on the student's educational background and work experience [7].

\section{CANDidate Profile}

- Taste for related themes to the sciences of mathematics and physics and technological ones of civil engineering.

- Interest in solving problems in engineering in coastal and estuary environment principally the ones that involves the coast and constructions.

- Capability of questioning.

- Affinity and discipline for the activity of research [8].

\section{EXPECTED OUTCOMES OF THE PROGRAM PROFESSIONAL PROFILE}

The engineer with an MBA in social engineering should present some characteristics as a professional. These expected characteristics are:

- Search constant updating and self-development through study and research, to propose innovations, identify and incorporate with criticism, new methods, techniques and technologies to their actions and respond to everyday situations and with unprecedented flexibility, creativity, resourcefulness as well as social and cultural.

- Taking professional attitude consistent with the principles governing the work area, working in multidisciplinary teams and relating appropriately with other professionals, clients and suppliers. 
- Manage the career with initiative and in an entrepreneurial way, to provide services or organizations to conduct own business.

- Acting responsibly, committing to the principles of ethics, environmental sustainability, the preservation of health and social development, directing its activities to the values expressed in the professional ethos, which results in quality and commitment with work well done.

These characteristics are important because a social engineer will deal with the aspects of human life that are imperative for the future of young generations. The achievements have a huge impact on how life will develop in a region or community in the years to come. Specialists working in the field of social engineering can make a huge contribution to the overall engineering profession [9].

\section{OBJeCtives of Program}

The main objectives of this social engineering graduation program are:

- to prepare engineering researchers and professionals in administrative positions who work in areas related to policy to design and implement in national territory socio-economic systems and to develop the integrated theories and methods of these areas;

- to increase logical thinking, sense of social ethics, social assessment capability;

- to start thinking without any preconceived notions;

- to look for innovative problem solving .

\section{FINAL DISCUSSIONS}

At this point some discussions should take place. We start with the definition of science, which states that it is a process of inquiry that involves questioning, hypothesizing, investigating, gathering evidence, organizing data, testing, refining, predicting, explaining and communicating. So the development of science is a long process that requires some personal skills that can be fostered along the education period of the human being. The achievement of knowledge in order to make science respond to human needs results in technology that men use to make life better. Due to the challenging characteristics of scientific knowledge application and development it is possible to say that it is in constant construction. This is what makes science and technology development so interesting and enticing for those professionals who are always seeking for new ways of working, meaning more effectively.

Presently the bachelor diploma is not enough to obtain success in a career. No doubt that a third degree diploma opens some doors. Therefore it means not only the possibility of earning more money but also to reach an upper status, socially speaking. However as the work market is more than ever extremely competitive and mutant life long learning is something that professionals should pursue.
It is a fact that online learning is not for everyone at this point of human development stage. It is very difficult to juggle work, family and study. Plenty of self-discipline is necessary. However, the idea to study at any time any place that suits the students best is very appealing. Another aspect is that it gives an opportunity for bright students in different remote parts of the world to access a top-quality education program, which would otherwise be unavailable to them. Distance-learning students tend to apply what they have learnt immediately in their work, making their studies more practical.

Competitive modern marketplace demands rapid change and innovation, for which distance education programs can act as a catalyst. It is a lifelong learning environment once it provides the students the opportunity to receive equal education regardless of income status, area of residence, gender, race, age, or cost per student. The proposed program delivered by COPEC constitutes another opportunity for engineers to acquire knowledge in their fields of expertise to defeat social problems mainly faced by urban agglomerations derived by the global population growth.

\section{ACKNOWLEDGMENT}

This work was partly funded by FEDER funds through the Operational Competitiveness Program (COMPETE) and by FCT with the projects PEst-C/CTM/UI0264/2011 and FCOMP-01-0124-FEDER-022674

\section{REFERENCES}

[1] Brito, C. da R.; Ciampi, M. M. Forming Engineers for a growing demand. In: International Conference on Engineering and Computer Education, 8., Luanda, 2013. Forming Engineers for a growing demand. Luanda: ICECE, 2013.

[2] Brito, C. da R.; Ciampi, M. M.; Amaral, L.; Vasconcelos, R Engineering and technology education turning challenges into opportunities. In: International Conference on Engineering and Technology Education, 12., East Timor, 2012. Engineering and Technology Education Turning Challenges into Opportunities. East Timor: INTERTECH, 2012.

[3] Brito, C. da R.; Ciampi, M. M.; Amaral, L.; Vasconcelos, R Study abroad program impacting engineering formation: Cultural Imersion (CIB). In: ASEE Annual Conference, 119., San Antonio, 2012. Proceedings. San Antonio: ASEE, 2012.

[4] Brito, C. da R.; Ciampi, M. M. Social-technological issues: Sustainable engineering practice. In: IGIP Annual Symposium, 41., Vilach, 2012. Collaborative Learning and New Pedagogical Approaches in Engineering Education. Villach: IGIP, 2012.

[5] Elaine O'Reilly, Algonquin College and Diane Alfred, Human Resources Development Canada; http://makingcareersense.org/

[6] Employability Skills Profile: http://www.conferenceboard.ca/libraries/educ_public/emskill.sflb.

[7] Taraman, K. S. The Competitiveness of a Union of the Americas. In: Internatiomal Conference on Engineering and Technology Education, 7., Santos, 2012. Engineering and Technology Education in the new Paradigm of Glogal Society. Santos: INTERTECH, 2012.

[8] Compete to Win Research Report, http://www.ic.gc.ca/eic/site/cprpgepmc.nsf/vwapj/Compete_to_Win.pdf

[9] Environmental Transformations in Developing Countries: Hybrid Research and Democratic Policy http://www.simonbatterbury.net/pubs/envttransformationsintro.pdf 